\title{
Phase 1 dose de-escalation trial of the endogenous folate [6R]-5,10-methylene tetrahydrofolate in combination with fixed-dose pemetrexed as neoadjuvant therapy in patients with resectable rectal cancer
}

\author{
Bengt Gustavsson $^{1}$ • Göran Carlsson ${ }^{1}$ - Torbjörn Swartling ${ }^{1}$ · Göran Kurlberg ${ }^{1}$ \\ Kristoffer Derwinger $^{1} \cdot$ Hillevi Björkqvist ${ }^{1} \cdot$ Elisabeth Odin $^{1} \cdot$ Fernando Gibson $^{2}$
}

Received: 25 March 2015 / Accepted: 7 July 2015 /Published online: 21 July 2015

(C) The Author(s) 2015. This article is published with open access at Springerlink.com

Summary Background Modufolin ${ }^{\circledR}$ ([6R]-5,10-methylene tetrahydrofolate; [6R]-MTHF) is an endogenous biomodulator that is being developed as an alternative to leucovorin, a folate prodrug used in the treatment of colorectal cancer. The objective of this phase 1 dose de-escalation trial was to estimate the minimum tolerated dose of [6R]-MTHF to be used in combination with pemetrexed $500 \mathrm{mg} / \mathrm{m}^{2}$ in the neoadjuvant treatment of patients with rectal cancer. Methods Adult patients ( $\geq 18$ years) with resectable rectal adenocarcinoma were allocated to [6R]-MTHF doses of $500,100,50$, and $10 \mathrm{mg} / \mathrm{m}^{2}$ in combination with pemetrexed $500 \mathrm{mg} / \mathrm{m}^{2}$. [6R]-MTHF was administered as an intravenous (i.v.) bolus injection 1 week prior to the first dose of pemetrexed and then once weekly for 9 weeks; pemetrexed was administered by i.v. infusion once every 21 days for three cycles. Results Twenty-four patients (mean [SD] age, 63.1 [12.9] years) were enrolled in the study. A total of 72 treatment-related adverse events (AEs) were reported, of which the most common were fatigue $(n=17$; $23.6 \%)$, nausea $(n=10 ; 13.9 \%)$, and diarrhea $(n=5 ; 6.9 \%)$. The incidence of treatment-related AEs by [6R]-MTHF dose level $\left(500,100,50,10 \mathrm{mg} / \mathrm{m}^{2}\right)$ was $11.1 \%(n=8), 13.9 \%$ $(n=10), 45.8 \%(n=33)$, and $29.2 \%(n=21)$, respectively.

Electronic supplementary material The online version of this article (doi:10.1007/s10637-015-0272-0) contains supplementary material, which is available to authorized users.

Fernando Gibson

fernando.gibson@pharmagenesis.com

1 Department of Surgery, University of Gothenburg, Sahlgrenska University Hospital/Östra Institute of Clinical Sciences, Gothenburg, Sweden

2 PharmaGenesis London, 9 Whitehall, 4th Floor, London SW1A 2DD, UK
There were no dose-limiting toxicities, and only two (2.8\%) treatment-related AEs were grade 3 in severity. Of the 11 serious AEs reported, none were considered to be related to [6R]-MTHF treatment. Conclusions The results of this phase 1 study indicate that the estimated minimum tolerated dose of [6R]-MTHF was $100 \mathrm{mg} / \mathrm{m}^{2}$ once weekly in combination with pemetrexed $500 \mathrm{mg} / \mathrm{m}^{2}$. The low toxicity profile of [6R]-MTHF supports its further evaluation as a component of systemic chemotherapy in the management of colon and rectal cancer.

Keywords [6R]-5,10-methylene tetrahydrofolate . Endogenous folate $\cdot$ Antifolates $\cdot$ Phase 1 trial $\cdot$ Pemetrexed . Neoadjuvant therapy $\cdot$ Rectal cancer

\section{Introduction}

The GLOBOCAN 2012 report ranks colorectal cancer as the third most commonly diagnosed cancer (1.36 million cases, $9.7 \%$ ) after lung and breast cancer, and the fourth highest cause of cancer death $(694,000$ deaths) behind lung, liver, and stomach cancer [1]. In the USA, rectal cancer accounts for approximately $25 \%$ of colorectal cancer cases [2], whereas across Europe, the reported proportion of rectal cancer cases is variable, ranging from 27 to $58 \%$ [3].

In patients with early ( $\mathrm{T} 1$ or $\mathrm{T} 2$ ) rectal cancers involving less than $40 \%$ of the circumference and without lymphovascular invasion, curative resection is a viable and effective therapeutic option [4]. However, for patients with locally advanced (T3 or T4) rectal cancer, the classical treatment approach consists of combined modality therapy, comprising radiation and chemotherapy in the adjuvant (postoperative) setting [5]. This algorithm was adopted in the 1990s, based on seminal studies 
which showed that adjuvant chemotherapy based on 5fluorouracil (5-FU), radiation, or combined chemoradiotherapy (CRT) significantly decreased the rates of local recurrence in patients with locally advanced rectal cancer when compared with resection alone [6-8].

The introduction of total mesorectal excision (TME) reduced the local recurrence rate to approximately $10 \%$, equivalent to that achieved with conventional surgery with adjuvant CRT [9-12]. These findings raised questions regarding the need for adjuvant CRT and whether neoadjuvant CRT might be superior to adjuvant CRT in improving patient outcomes. Although there is no overall or disease-free survival benefit for neoadjuvant compared with adjuvant CRT [13-16], multiple phase 3 studies have demonstrated that neoadjuvant fluoropyrimidine-based CRT decreases local recurrence rates, induces tumor downstaging, improves the odds of anal sphincter preservation, and increases response rates compared with adjuvant CRT [17-21]. These findings led to the adoption of neoadjuvant CRT followed by TME and adjuvant chemotherapy as the current standard of care for the treatment of locally advanced rectal cancer [22, 23].

Despite the improved local control with neoadjuvant CRT, approximately a third of patients develop distant metastases [24]. With this in mind, strenuous efforts have been made to investigate various combinations and dosing schedules of chemotherapeutic agents with the aim of improving the safety and efficacy of neoadjuvant CRT [25]. The reduced folate leucovorin (5-formyl tetrahydrofolate) potentiates the cytotoxic activity of 5-FU, an inhibitor of thymidylate synthase [26-30], and is an important component of fluoropyrimidine-based chemotherapy in the treatment of colorectal cancer $[31,32]$. However, leucovorin is a prodrug that requires metabolic conversion to the active cofactor [6R]5,10-methylene tetrahydrofolate ([6R]-MTHF; Fig. 1). In the presence of 5-FU, MTHF forms a stable, ternary complex with 5-fluorodeoxyuridine monophosphate and thymidylate synthase, thereby inhibiting thymidylate synthase activity
[33-35]. MTHF levels have been shown to be among the lowest of the reduced folates in tumor cells following leucovorin administration [36], suggesting the hypothesis that the direct administration of MTHF might provide superior antitumor activity to that of leucovorin, particularly in patients who convert leucovorin to MTHF at a slow rate or catabolize leucovorin rapidly. Preclinical data in support of this idea was provided by Carlsson et al. [37], who found that the administration of 5-FU in combination with MTHF completely eliminated tumor take in rats inoculated with colon adenocarcinoma cells.

Pemetrexed is a folate analogue that inhibits several folatedependent enzymes in addition to thymidylate synthase, and was therefore thought to have theoretical advantages over fluoropyrimidines in the treatment of colorectal cancer [38]. Underhill et al. [39] reported the results of a randomized phase 2 trial of pemetrexed plus irinotecan (ALIRI) versus 5-FU plus leucovorin plus irinotecan (FOLFIRI) in patients with advanced or metastatic colorectal cancer. Progression-free survival in the ALIRI arm was significantly shorter than in the FOLFIRI arm (ALIRI, 5.7 months; FOLFIRI, 7.7 months; $p<0.001$ ), and the number of drug-related deaths was higher (ALIRI, 4; FOLFIRI, 1), indicating that pemetrexed is not superior to 5-FU-based therapy in the treatment of metastatic colorectal cancer, in terms of either efficacy or safety. However, a phase $1 / 2$ feasibility trial of preoperative pemetrexed therapy in patients with resectable rectal cancer showed a significant reduction of tumor size $(p<0.001)$ and tumorrelated symptoms $(p<0.018)$, with a low incidence $(10.8 \%)$ of grade 3 or 4 adverse effects [40], indicating that pemetrexed is a promising treatment option in the neoadjuvant setting.

Modufolin ${ }^{\circledR}$ (Isofol Medical AB, Gothenburg, Sweden) is a pure, stable formulation of the [6R]-diastereoisomer of MTHF that was developed as an alternative to leucovorin for the treatment of colon and rectal cancer [41]. Wettergren et al. [42] recently reported the results of a comparative pharmacokinetic/pharmacodynamic study of [6R]-MTHF
Fig. 1 Overview of folate metabolism. Abbreviations: $D H F$ dihydrofolate, $D H F R$ dihydrofolate reductase, $d T M P$ deoxythymidine monophosphate, $d U M P$ deoxyuridine monophosphate, MTHFD methylene tetrahydrofolate dehydrogenase, MTHFR methylene tetrahydrofolate reductase, $M T H F S$ methylene tetrahydrofolate synthase, SHMT1 serine hydroxymethyl transferase $1, T H F$ tetrahydrofolate, $T S$ thymidylate synthase

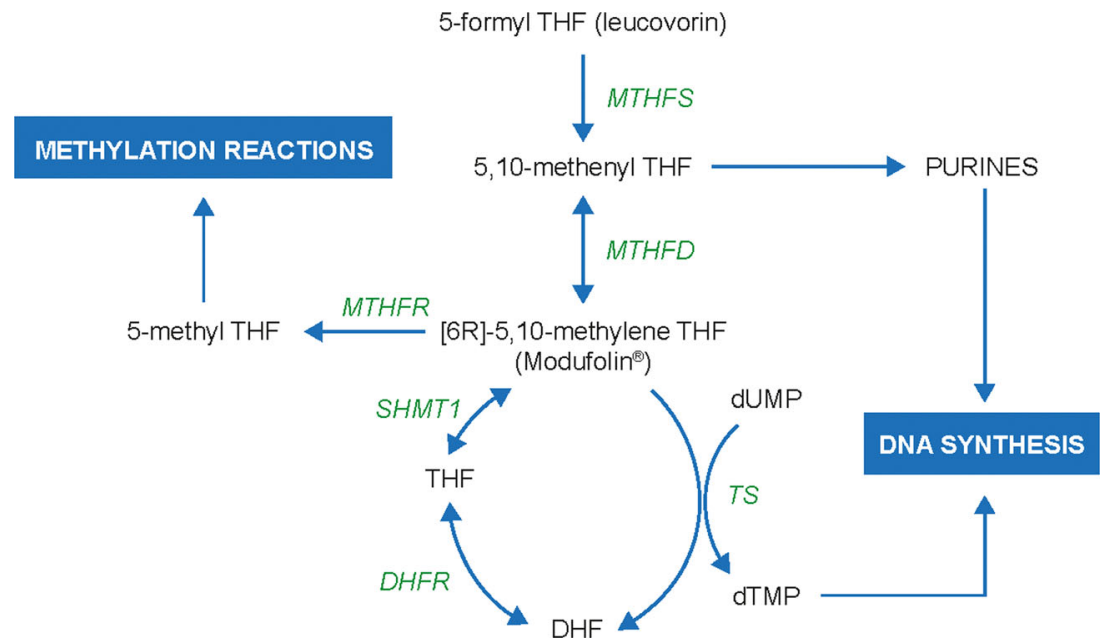


and leucovorin in patients with colon cancer. The administration of [6R]-MTHF resulted in significantly $(p<0.01)$ higher concentrations of MTHF in mucosa and tumors than were seen following leucovorin administration.

The objective of this phase 1 dose de-escalation trial was to estimate the minimum tolerated dose of [6R]-MTHF to be used in combination with pemetrexed $500 \mathrm{mg} / \mathrm{m}^{2}$ in the neoadjuvant treatment of patients with resectable rectal cancer.

\section{Methods}

\section{Patients}

Adult patients ( $\geq 18$ years of age) with histologically confirmed, resectable adenocarcinoma of the rectum were eligible for inclusion in this single-center, phase 1, open-label, dose de-escalation trial (ISO-MC-091; ClinicalTrials.gov: NCT01397305; EudraCT 2009-009999-12A). The study was conducted between 14 April 2011 and 16 May 2014. Patients were required to have adequate hematologic function (hemoglobin $\geq 9 \mathrm{~g} / \mathrm{L}$, neutrophils $\geq 1.5 \times 10^{9} / \mathrm{L}$, platelet count $\geq 100 \times 10^{9} / \mathrm{L}$ ), hepatobiliary function (serum bilirubin $<1.5 \times$ upper limit of normal range [ULNR], alkaline phosphatase $<3 \times$ ULNR, aspartate aminotransferase $<3 \times$ ULNR), and renal function (estimated Cockcroft clearance $\geq 45 \mathrm{~mL} / \mathrm{min}$ ).

Patients were excluded if they had a concurrent, uncontrolled medical illness, or previous or current malignant disease.

Baseline screening evaluations comprised a complete medical examination, including blood cell count and routine blood chemistry, and tumor assessment using radiography. Pretreatment radiological investigations included a chest X-ray and magnetic resonance imaging (MRI) scans of the upper abdomen (liver) and pelvis. A second MRI scan of the liver and pelvis was performed after completion of the three pemetrexed treatment cycles (as described in the study treatment section below) and before surgery. Staging was performed on pelvic T2-weighted images and a quantitative value of tumor size was measured as the maximal tumor area $\left(\mathrm{mm}^{2}\right)$ on oblique axial $\mathrm{T} 2$-weighted images. Post-operative radiological evaluations and tumor outcomes were assessed according to the Response Evaluation Criteria in Solid Tumours (RECIST) criteria [43].

The trial was conducted with local ethical committee approval and in accordance with Good Clinical Practice and the Declaration of Helsinki. All patients provided written informed consent.

\section{Study treatment and [6R]-MTHF dose de-escalation}

Treatment commenced within 4 weeks of the completion of assessments of eligibility. This phase 1 trial utilized a dose deescalation design to determine the minimum tolerated dose of [6R]-MTHF that is able to abrogate pemetrexed-associated toxicity. In an initial segment of the trial, patients were sequentially assigned to [6R]-MTHF doses of 100,50 , and $10 \mathrm{mg} / \mathrm{m}^{2}$, with intrapatient dose de-escalation not permitted. A cohort of six patients was treated at each [6R]-MTHF dose level; however, one patient assigned to receive [6R]-MTHF $10 \mathrm{mg} / \mathrm{m}^{2}$ was erroneously given a dose of $50 \mathrm{mg} / \mathrm{m}^{2}$. Patients were only treated at the next (lower) [6R]-MTHF dose if $\leq 2$ of the 6 $(\leq 33.3 \%)$ patients reported a dose-limiting toxicity, defined as a grade 3 or 4 drug-related hematologic or gastrointestinal toxicity [44] at the current dose. Following a preliminary analysis of safety data, the study protocol was amended to include an additional [6R]-MTHF dose of $500 \mathrm{mg} / \mathrm{m}^{2}$.

[6R]-MTHF was administered as an intravenous (i.v.) bolus injection 1 week prior to the first dose of pemetrexed and then once weekly for 9 weeks; pemetrexed $500 \mathrm{mg} / \mathrm{m}^{2}$ was administered by i.v. infusion once every 21 days for three cycles. Concomitant medication included vitamin B12 $1000 \mu \mathrm{g}$ by intramuscular injection $1-2$ weeks prior to the first dose of pemetrexed, and thereafter approximately once every 9 weeks, and two dexamethasone $4 \mathrm{mg}$ oral doses on the day before, the day of, and the day after each administration of pemetrexed. Furthermore, if deemed indicated by the treating
Table 1 Baseline demographics and disease characteristics

\begin{tabular}{|c|c|c|c|c|c|}
\hline & \multicolumn{4}{|c|}{ [6R]-MTHF dose, $\mathrm{mg} / \mathrm{m}^{2}$} & \multirow[t]{2}{*}{ Overall } \\
\hline & 500 & 100 & 50 & 10 & \\
\hline Patients, $\mathrm{n}$ & 6 & 6 & 7 & 5 & 24 \\
\hline Age, years, mean (SD) & $58.17(8.8)$ & $62.33(16.0)$ & $68.57(14.3)$ & $62.40(11.9)$ & $63.1(12.9)$ \\
\hline \multicolumn{6}{|l|}{ Sex, n $(\%)$} \\
\hline Female & $4(66.7)$ & $3(50.0)$ & $2(28.6)$ & $1(20.0)$ & $10(41.7)$ \\
\hline Male & $2(33.3)$ & $3(50.0)$ & $5(71.4)$ & $4(80.0)$ & $14(58.3)$ \\
\hline Tumor stage (I/II/III/IV) & $0 / 2 / 4 / 0$ & $0 / 1 / 4 / 1$ & $0 / 1 / 5 / 0^{\mathrm{a}}$ & $0 / 2 / 3 / 0$ & $0 / 6 / 16 / 1$ \\
\hline
\end{tabular}

Abbreviations: $M T H F$ 5,10-methylene tetrahydrofolate, $S D$ standard deviation

${ }^{\text {a }}$ Staging data is missing for one patient in the $50 \mathrm{mg} / \mathrm{m} 2$ group because the patient was withdrawn before final staging could be done 
Table 2 [6R]-MTHF dose de-escalation schedule

\begin{tabular}{lll}
\hline$[6 \mathrm{R}]-\mathrm{MTHF}$ dose, $\mathrm{mg} / \mathrm{m}^{2}$ & Patients, $\mathrm{n}$ & Doses, $\mathrm{n}^{\mathrm{a}}$ \\
\hline 500 & 6 & 60 \\
100 & 6 & 60 \\
50 & 7 & 70 \\
10 & 5 & 50 \\
Total & 24 & 240 \\
\hline
\end{tabular}

Abbreviation: MTHF 5,10-methylene tetrahydrofolate

${ }^{a}$ All patients received 10 once-weekly doses of [6R]-MTHF, plus pemetrexed $500 \mathrm{mg} / \mathrm{m}^{2}$ every 21 days, for three cycles

physician and the multidisciplinary team at the hospital, patients received radiotherapy for 5 consecutive days (at the earliest on day 17 in cycle 3 ) as standard care before surgery. Treatment was discontinued in the case of disease progression, unacceptable toxicity, or withdrawal of patient consent.

\section{Toxicity assessment}

Adverse events (AEs) were assessed using the Medical Dictionary for Regulatory Activities v11.0 and graded according to the National Cancer Institute Common Terminology Criteria for Adverse Events (NCI CTCAE) v3.0 as toxicity grade 1 (mild), grade 2 (moderate), grade 3 (severe), grade 4 (life-threatening or disabling), or grade 5 (death related to AE) [44]. The relationship of each AE to study drugs and/or procedures was assessed by the investigator. No distinction was made regarding relationship to [6R]-MTHF or pemetrexed unless the AE fulfilled the criteria of a serious $\mathrm{AE}$, which was defined as a life-threatening $\mathrm{AE}$, inpatient hospitalization or prolongation of existing hospitalization, a persistent or significant incapacity or substantial disruption of the ability to conduct normal life functions, or a congenital anomaly/birth defect [45].

\section{Results \\ Patients and dose de-escalation schedule}

A total of 24 patients with resectable adenocarcinoma of the rectum (mean age, 63.1 years) were enrolled in the trial and assigned to [6R]-MTHF $500 \mathrm{mg} / \mathrm{m}^{2} \quad(n=6)$, $100 \mathrm{mg} / \mathrm{m}^{2}(n=6), 50 \mathrm{mg} / \mathrm{m}^{2}(n=7)$, and $10 \mathrm{mg} / \mathrm{m}^{2}$ $(n=5)$. Baseline demographics are summarized in Table 1. The [6R]-MTHF dose de-escalation schedule is shown in Table 2.

\section{Toxicity assessments}

Of the 24 enrolled patients, 22 experienced at least one treatment-emergent AE during the study (Table 3). An initial total of 172 treatment-emergent AEs were reported, of which 13 were procedure-related (related to the surgical procedure). After correction for multiple reporting of the same AE code by the same patient, 128 unique treatment-emergent AEs remained. A comprehensive listing of all treatment-emergent AEs is presented in Online Resource 1.

The incidence of treatment-emergent AEs by [6R]-MTHF dose level $\left(500,100,50,10 \mathrm{mg} / \mathrm{m}^{2}\right)$ was $18.8 \%(n=24)$, $12.5 \%(n=16), 40.6 \%(n=52)$, and $28.1 \%(n=36)$, respectively (Table 3$)$. The most frequently reported treatmentemergent AEs were fatigue $(n=18 ; 14.1 \%)$ and nausea $(n=$ $11 ; 8.6 \%)$; only one of each AE was toxicity grade 3 (Table 4).
Table 3 Overview of adverse events

\begin{tabular}{llllll}
\hline & \multicolumn{2}{l}{ [6R]-MTHF dose, $\mathrm{mg} / \mathrm{m}^{2}$} & \\
\cline { 2 - 5 } & 500 & 100 & 50 & 10 & Total, n (\%) \\
\hline Patients, $\mathrm{n}$ & 6 & 6 & 7 & 5 & 24 \\
Patients with $\geq 1$ treatment-emergent AE, $\mathrm{n}$ & 4 & 6 & 7 & 5 & 22 \\
Treatment-emergent AEs, $\mathrm{n}(\%)$ & $24(18.8)$ & $16(12.5)$ & $52(40.6)$ & $36(28.1)$ & $128(100)$ \\
Patients with $\geq 1$ serious AE, $\mathrm{n}$ & 1 & 0 & 3 & 1 & 5 \\
Serious AEs, $\mathrm{n}(\%)^{\mathrm{a}}$ & $1(0.8)$ & 0 & $9(7.0)$ & $1(0.8)$ & $11(8.6)$ \\
Patients with $\geq 1$ treatment-related AE, $\mathrm{n}$ & 2 & 6 & 7 & 5 & 20 \\
Treatment-related AEs, $\mathrm{n}(\%)$ & $8(11.1)$ & $10(13.9)$ & $33(45.8)$ & $21(29.2)$ & $72(100)$ \\
Patients discontinued due to AEs, $\mathrm{n}$ & 0 & 0 & 0 & 0 & 0 \\
Deaths, $\mathrm{n}$ & 0 & 0 & 0 & 0 & 0 \\
\hline
\end{tabular}

All patients received the indicated dose of [6R]-MTHF plus pemetrexed $500 \mathrm{mg} / \mathrm{m}^{2}$. Data presented are the number of unique AEs after correction for multiple reporting of of the same AE code by a patient

Abbreviations: AE adverse event, MTHF 5,10-methylene tetrahydrofolate

${ }^{a}$ Percentages based on the total number of treatment-emergent AEs $(n=128)$ 
Table 4 Treatment-emergent adverse events with an incidence of $\geq 5 \%$

\begin{tabular}{|c|c|c|c|c|c|c|c|c|c|c|c|c|c|c|}
\hline \multirow{2}{*}{$\begin{array}{l}{[6 \mathrm{R}]-\mathrm{MTHF} \text { dose, } \mathrm{mg} / \mathrm{m}^{2}} \\
\text { Patients, } \mathrm{n} \\
\text { Toxicity grade }\end{array}$} & \multicolumn{3}{|c|}{$\begin{array}{l}500 \\
6\end{array}$} & \multicolumn{3}{|l|}{$\begin{array}{l}100 \\
6\end{array}$} & \multicolumn{3}{|l|}{$\begin{array}{l}50 \\
7\end{array}$} & \multicolumn{4}{|l|}{$\begin{array}{l}10 \\
5\end{array}$} & \multirow[b]{2}{*}{ Total, n (\%) } \\
\hline & 1 & 2 & 3 & 1 & 2 & 3 & 1 & 2 & 3 & 1 & 2 & 3 & 4 & \\
\hline \multicolumn{15}{|c|}{ Treatment-emergent AEs, $\mathrm{n}$} \\
\hline All & 17 & 5 & 2 & 14 & 2 & & 37 & 10 & 5 & 26 & 8 & 1 & 1 & $128(100)$ \\
\hline Fatigue & 2 & & & 4 & & & 5 & 1 & 1 & 4 & 1 & & & $18(14.1)$ \\
\hline Nausea & 2 & & & 2 & & & 2 & 2 & 1 & & 2 & & & $11(8.6)$ \\
\hline Pain & 2 & & & 1 & & & & 1 & 1 & & 2 & & & $7(5.5)^{\mathrm{a}}$ \\
\hline
\end{tabular}

Data presented are the number of unique treatment-emergent AEs after correction for multiple reporting of the same AE code by a patient

Abbreviations: $A E$ adverse event, $M T H F$ 5,10-methylene tetrahydrofolate

${ }^{a}$ Aggregate incidence of all pain-related AEs, comprising general pain, abdominal pain, headache, lower leg pain, other leg pain, rectal pain, and shoulder pain
A total of 72 treatment-related AEs were reported by 20 patients (Table 5). The incidence of treatment-related AEs by [6R]-MTHF dose level $\left(500,100,50,10 \mathrm{mg} / \mathrm{m}^{2}\right)$ was $11.1 \%$ $(n=8), 13.9 \%(n=10), 45.8 \%(n=33)$, and $29.2 \%(n=21)$, respectively (Table 3 ). The most frequent treatment-related AEs were fatigue $(n=17 ; 23.6 \%)$ and nausea $(n=10$; $13.9 \%)$. Two treatment-related AEs were toxicity grade 3 (Table 5).

Overall, [6R]-MTHF in combination with pemetrexed was associated with a low toxicity profile. No doselimiting toxicities were reported during the study, and there were no treatment-related grade 4 or 5 AEs. A total of 11 serious AEs (SAEs) were reported; however, none of these were considered to be related to [6R]-MTHF treatment (Table 3). One SAE (fever) was judged to be related to pemetrexed, four were procedure-related (postoperative wound complication, infection, anastomotic leak, abscess [local anastomosis]), and the rest were considered not to be treatment- or procedure-related. Finally, there were no deaths during the study, and no patients discontinued the study due to AEs or SAEs.

\section{Discussion}

[6R]-MTHF is an enantiomerically pure formulation of the endogenous, biologically active isomer of MTHF [46]. Clinical trials are in progress to evaluate the safety and efficacy of [6R]-MTHF as an alternative to leucovorin in potentiating the activity of 5-FU and the antifolates (including pemetrexed, raltitrexed, pralatrexate, and methotrexate) in the treatment of patients with colon and rectal cancer. Leucovorin is a prodrug that requires metabolic conversion to the active cofactor MTHF [36], and a corollary of this is that leucovorin administration is associated with considerable intra- and interpatient variability in plasma, tumor, and mucosa MTHF levels [47-50]. Thus, we hypothesized that direct administration of MTHF might provide higher intratumor concentrations of MTHF and, therefore, greater antitumor activity than that seen with leucovorin. Indeed, Wettergren et al. [42] recently showed that administration of [6R]-MTHF $200 \mathrm{mg} / \mathrm{m}^{2}$ resulted in significantly higher MTHF levels in mucosa and tumor tissue in patients with colon cancer, when compared with administration of leucovorin $200 \mathrm{mg} / \mathrm{m}^{2}$. However, it has still
Table 5 Treatment-related adverse events with an incidence of $\geq 5 \%$

\begin{tabular}{|c|c|c|c|c|c|c|c|c|c|c|c|c|c|}
\hline \multirow{2}{*}{$\begin{array}{l}{[6 \mathrm{R}]-\mathrm{MTHF} \text { dose, } \mathrm{mg} / \mathrm{m}^{2}} \\
\text { Patients, } \mathrm{n} \\
\text { Toxicity grade }\end{array}$} & \multicolumn{3}{|c|}{$\begin{array}{l}500 \\
6\end{array}$} & \multicolumn{3}{|c|}{$\begin{array}{l}100 \\
6\end{array}$} & \multicolumn{3}{|l|}{$\begin{array}{l}50 \\
7\end{array}$} & \multicolumn{3}{|c|}{$\begin{array}{l}10 \\
5\end{array}$} & \multirow[b]{2}{*}{ Total, n (\%) } \\
\hline & 1 & 2 & 3 & 1 & 2 & 3 & 1 & 2 & 3 & 1 & 2 & 3 & \\
\hline \multicolumn{14}{|l|}{ Treatment-related AEs, $n$} \\
\hline All & 8 & & & 10 & & & 33 & & & 21 & & & $72(100)$ \\
\hline Fatigue & 2 & & & 2 & 2 & & 2 & 4 & & 4 & 1 & & $17(23.6)$ \\
\hline Nausea & 2 & & & 2 & & & 2 & 2 & & & 2 & & $10(13.9)$ \\
\hline Diarrhea & & & & & & & 2 & & 1 & & 1 & 1 & $5(6.9)$ \\
\hline
\end{tabular}

Data presented are the number of unique treatment-related AEs after correction for multiple reporting of the same AE code by a patient

No distinction was made regarding relationship to [6R]-MTHF or pemetrexed unless AEs were assessed as serious AEs

Abbreviations: $A E$ adverse event, $M T H F$ 5,10-methylene tetrahydrofolate 
to be demonstrated that higher intratumor levels of MTHF translate into superior efficacy in terms of tumor response rates and overall survival.

In the current study, we utilized a dose de-escalation design to identify the optimum dose of [6R]-MTHF to be used in combination with pemetrexed $500 \mathrm{mg} / \mathrm{m}^{2}$. The rationale behind the de-escalation design was that [6R]-MTHF was acting as a substitute for folic acid, which is routinely given (together with vitamin B12) to patients receiving pemetrexed in order to minimize the risk of severe toxicity [51-53]. Therefore, a key objective was to identify the minimum tolerated dose of [6R]MTHF that can be used in combination with pemetrexed $500 \mathrm{mg} / \mathrm{m}^{2}$. Although there were no dose-limiting toxicities at any of the four [6R]-MTHF dose levels, the incidence of treatment-related AEs was markedly lower at the two higher [6R]-MTHF doses (500 mg/m² $11.1 \% ; 100 \mathrm{mg} / \mathrm{m}^{2}, 13.9 \%$ ) than at the two lower doses $\left(50 \mathrm{mg} / \mathrm{m}^{2}, 45.8 \%, 10 \mathrm{mg} / \mathrm{m}^{2}\right.$, $29.2 \%$ ), suggesting that [6R]-MTHF was able to modulate the toxicity of pemetrexed in a dose-dependent manner. Given that the incidence of treatment-related AEs was similar at [6R]-MTHF 500 and $100 \mathrm{mg} / \mathrm{m}^{2}$, the minimum tolerated [6R]-MTHF dose was estimated to be $100 \mathrm{mg} / \mathrm{m}^{2}$ once weekly.

The most frequent treatment-related AEs were grade $1 \mathrm{fa}-$ tigue, nausea, and diarrhea, which are common side effects of pemetrexed therapy [54]. In contrast to previous trials of pemetrexed in patients with colorectal cancer, none of the patients in the current study reported instances of grade $3 / 4$ neutropenia [39, 40, 55]. However, this was a phase 1 study, and larger phase $2 / 3$ studies will provide a more rigorous evaluation of the safety and tolerability of [6R]-MTHF plus pemetrexed combination therapy. With regard to SAEs, none were considered to be related to [6R]-MTHF, corroborating the toxicity findings of Wettergren et al. [42], who reported that no AEs/SAEs were related to [6R]-MTHF treatment.

\section{Conclusions}

In this phase 1 dose de-escalation trial, [6R]-MTHF doses ranging from $500 \mathrm{mg} / \mathrm{m}^{2}$ down to $10 \mathrm{mg} / \mathrm{m}^{2}$, in combination with pemetrexed $500 \mathrm{mg} / \mathrm{m}^{2}$, showed a low toxicity profile in patients with resectable rectal cancer. The estimated minimum tolerated dose of [6R]-MTHF was $100 \mathrm{mg} / \mathrm{m}^{2}$ once weekly. Phase 2 studies are in progress to further assess the safety, tolerability, and efficacy of [6R]-MTHF as a component of systemic chemotherapy in the management of colon and rectal cancer.

\section{Compliance with ethical standards}

Ethical approval All procedures performed in studies involving human participants were in accordance with the ethical standards of the institutional and/or national research committee and with the 1964 Helsinki declaration and its later amendments or comparable ethical standards.

Informed consent Informed consent was obtained from all participants included in the study.

Funding Isofol Medical AB, Gothenburg, Sweden, sponsored this study.

Conflict of interest B. Gustavsson is a Director of Isofol Medical AB. F. Gibson is an employee of PharmaGenesis London, UK, which received payment from Isofol Medical AB.

Open Access This article is distributed under the terms of the Creative Commons Attribution 4.0 International License (http:// creativecommons.org/licenses/by/4.0/), which permits unrestricted use, distribution, and reproduction in any medium, provided you give appropriate credit to the original author(s) and the source, provide a link to the Creative Commons license, and indicate if changes were made.

\section{References}

1. Ferlay J, Soerjomataram I, Ervik M, Dikshit R, Eser S, Mathers C, Rebelo M, Parkin DM, Forman D, Bray F (2013) GLOBOCAN 2012 v1.0, Cancer Incidence and Mortality Worldwide: IARC CancerBase No. 11. International Agency for Research on Cancer, Lyon

2. Jemal A, Bray F, Center MM, Ferlay J, Ward E, Forman D (2011) Global cancer statistics. CA Cancer J Clin 61(2):69-90

3. Brenner H, Bouvier AM, Foschi R, Hackl M, Larsen IK, Lemmens V, Mangone L, Francisci S (2012) Progress in colorectal cancer survival in Europe from the late 1980s to the early 21st century: the EUROCARE study. Int J Cancer 131(7):1649-1658

4. Stamos MJ, Murrell Z (2007) Management of early rectal T1 and T2 cancers. Clin Cancer Res 13(22 Pt 2):6885-6889

5. (1990) Adjuvant therapy for patients with colon and rectum cancer. Consens Statement 8(4):1-25

6. Fisher B, Wolmark N, Rockette H, Redmond C, Deutsch M, Wickerham DL, Fisher ER, Caplan R, Jones J, Lerner H et al (1988) Postoperative adjuvant chemotherapy or radiation therapy for rectal cancer: results from NSABP protocol R-01. J Natl Cancer Inst 80(1):21-29

7. Douglass HO Jr, Moertel CG, Mayer RJ, Thomas PR, Lindblad AS, Mittleman A, Stablein DM, Bruckner HW (1986) Survival after postoperative combination treatment of rectal cancer. N Engl J Med 315(20):1294-1295

8. Krook JE, Moertel CG, Gunderson LL, Wieand HS, Collins RT, Beart RW, Kubista TP, Poon MA, Meyers WC, Mailliard JA et al (1991) Effective surgical adjuvant therapy for high-risk rectal carcinoma. N Engl J Med 324(11):709-715

9. Heald RJ, Ryall RD (1986) Recurrence and survival after total mesorectal excision for rectal cancer. Lancet 1(8496):1479-1482

10. Enker WE, Thaler HT, Cranor ML, Polyak T (1995) Total mesorectal excision in the operative treatment of carcinoma of the rectum. J Am Coll Surg 181(4):335-346

11. MacFarlane JK, Ryall RD, Heald RJ (1993) Mesorectal excision for rectal cancer. Lancet 341(8843):457-460

12. Hainsworth PJ, Egan MJ, Cunliffe WJ (1997) Evaluation of a policy of total mesorectal excision for rectal and rectosigmoid cancers. Br J Surg 84(5):652-656 
13. Park JH, Yoon SM, Yu CS, Kim JH, Kim TW, Kim JC (2011) Randomized phase 3 trial comparing preoperative and postoperative chemoradiotherapy with capecitabine for locally advanced rectal cancer. Cancer 117(16):3703-3712

14. Roh MS, Colangelo LH, O'Connell MJ, Yothers G, Deutsch M, Allegra CJ, Kahlenberg MS, Baez-Diaz L, Ursiny CS, Petrelli NJ et al (2009) Preoperative multimodality therapy improves diseasefree survival in patients with carcinoma of the rectum: NSABP R-03. J Clin Oncol 27(31):5124-5130

15. Sauer R, Becker H, Hohenberger W, Rodel C, Wittekind C, Fietkau R, Martus P, Tschmelitsch J, Hager E, Hess CF et al (2004) Preoperative versus postoperative chemoradiotherapy for rectal cancer. N Engl J Med 351(17):1731-1740

16. Sauer R, Liersch T, Merkel S, Fietkau R, Hohenberger W, Hess C, Becker H, Raab HR, Villanueva MT, Witzigmann H et al (2012) Preoperative versus postoperative chemoradiotherapy for locally advanced rectal cancer: results of the German CAO/ARO/AIO-94 randomized phase III trial after a median follow-up of 11 years. J Clin Oncol 30(16):1926-1933

17. Bonnetain F, Bosset JF, Gerard JP, Calais G, Conroy T, Mineur L, Bouche O, Maingon P, Chapet O, Radosevic-Jelic L et al (2012) What is the clinical benefit of preoperative chemoradiotherapy with 5FU/leucovorin for T3-4 rectal cancer in a pooled analysis of EORTC 22921 and FFCD 9203 trials: surrogacy in question? Eur J Cancer 48(12): 1781-1790

18. De Caluwe L, Van Nieuwenhove Y, Ceelen WP (2013) Preoperative chemoradiation versus radiation alone for stage II and III resectable rectal cancer. Cochrane Database Syst Rev 2:CD006041

19. Ceelen WP, Van Nieuwenhove Y, Fierens K (2009) Preoperative chemoradiation versus radiation alone for stage II and III resectable rectal cancer. Cochrane Database Syst Rev 1:CD006041

20. Bosset JF, Collette L, Calais G, Mineur L, Maingon P, RadosevicJelic L, Daban A, Bardet E, Beny A, Ollier JC (2006) Chemotherapy with preoperative radiotherapy in rectal cancer. $\mathrm{N}$ Engl J Med 355(11):1114-1123

21. Gerard JP, Conroy T, Bonnetain F, Bouche O, Chapet O, ClosonDejardin MT, Untereiner M, Leduc B, Francois E, Maurel J et al (2006) Preoperative radiotherapy with or without concurrent fluorouracil and leucovorin in T3-4 rectal cancers: results of FFCD 9203. J Clin Oncol 24(28):4620-4625

22. Engstrom PF, Arnoletti JP, Benson AB 3rd, Chen YJ, Choti MA, Cooper HS, Covey A, Dilawari RA, Early DS, Enzinger PC et al (2009) NCCN clinical practice guidelines in oncology: colon cancer. J Natl Compr Canc Netw 7(8):778-831

23. Glimelius B, Tiret E, Cervantes A, Arnold D (2013) Rectal cancer: ESMO Clinical Practice Guidelines for diagnosis, treatment and follow-up. Ann Oncol 24(Suppl 6):vi81-vi88

24. Klautke G, Fietkau R (2007) Intensified neoadjuvant radiochemotherapy for locally advanced rectal cancer: a review. Int J Colorectal Dis 22(5):457-465

25. Martin LK, Bekaii-Saab T (2013) Optimizing neoadjuvant therapy for rectal cancer with oxaliplatin. J Natl Compr Canc Netw 11(3): 298-307

26. Evans RM, Laskin JD, Hakala MT (1981) Effect of excess folates and deoxyinosine on the activity and site of action of 5-fluorouracil. Cancer Res 41(9 Pt 1):3288-3295

27. Houghton JA, Maroda SJ Jr, Phillips JO, Houghton PJ (1981) Biochemical determinants of responsiveness to 5-fluorouracil and its derivatives in xenografts of human colorectal adenocarcinomas in mice. Cancer Res 41(1):144-149

28. Keyomarsi K, Moran RG (1986) Folinic acid augmentation of the effects of fluoropyrimidines on murine and human leukemic cells. Cancer Res 46(10):5229-5235

29. Rustum YM, Trave F, Zakrzewski SF, Petrelli N, Herrera L, Mittelman A, Arbuck SG, Creaven PJ (1987) Biochemical and pharmacologic basis for potentiation of 5-fluorouracil action by leucovorin. NCI Monogr 5:165-170

30. Ullman B, Lee M, Martin DW Jr, Santi DV (1978) Cytotoxicity of 5-fluoro-2'-deoxyuridine: requirement for reduced folate cofactors and antagonism by methotrexate. Proc Natl Acad Sci U S A 75(2): 980-983

31. (1995) Efficacy of adjuvant fluorouracil and folinic acid in colon cancer. International multicentre pooled analysis of colon cancer trials (IMPACT) investigators. Lancet 345(8955):939-944

32. Thirion P, Michiels S, Pignon JP, Buyse M, Braud AC, Carlson RW, O'Connell M, Sargent P, Piedbois P (2004) Modulation of fluorouracil by leucovorin in patients with advanced colorectal cancer: an updated meta-analysis. J Clin Oncol 22(18):3766-3775

33. Danenberg PV (1977) Thymidylate synthetase - a target enzyme in cancer chemotherapy. Biochim Biophys Acta 473(2):73-92

34. Santi DV, McHenry CS, Sommer H (1974) Mechanism of interaction of thymidylate synthetase with 5-fluorodeoxyuridylate. Biochemistry 13(3):471-481

35. van der Wilt CL, Pinedo HM, de Jong M, Peters GJ (1993) Effect of folate diastereoisomers on the binding of 5-fluoro-2'-deoxyuridine5 '-monophosphate to thymidylate synthase. Biochem Pharmacol 45(5):1177-1179

36. Boarman DM, Allegra CJ (1992) Intracellular metabolism of 5formyl tetrahydrofolate in human breast and colon cell lines. Cancer Res 52(1):36-44

37. Carlsson G, Hafstrom LO, Spears CP, Gustavsson B, Larsson PA (1997) 5-fluorouracil (5-FU) and 5,10-methylene tetrahydrofolate $(5,10-\mathrm{CH} 2 \mathrm{FH} 4)$ as adjuvant therapy in an experimental rodent colon carcinoma model. Anticancer Res 17(5A):3671-3674

38. Hochster H (2002) The role of pemetrexed in the treatment of colorectal cancer. Semin Oncol 29(6 Suppl 18):54-56

39. Underhill C, Goldstein D, Gorbounova VA, Biakhov MY, Bazin IS, Granov DA, Hossain AM, Blatter J, Kaiser C, Ma D (2007) A randomized phase II trial of pemetrexed plus irinotecan (ALIRI) versus leucovorin-modulated 5-FU plus irinotecan (FOLFIRI) in first-line treatment of locally advanced or metastatic colorectal cancer. Oncology 73(1-2):9-20

40. Derwinger K, Kodeda K, Swartling T, Kalebo P, Carlsson G, Gustavsson B (2011) A phase I/II study of neoadjuvant chemotherapy with Pemetrexed (Alimta) in rectal cancer. Eur J Surg Oncol 37(7):583-588

41. Isofol Medical AB: Modufolin ${ }^{\circledR}$. Available at: http://www. isofolmedical.se/modufolin.aspx. Accessed 24 Nov 2014

42. Wettergren Y, Taflin H, Odin E, Kodeda K, Derwinger K (2015) A pharmacokinetic and pharmacodynamic investigation of Modufolin(R) compared to Isovorin(R) after single dose intravenous administration to patients with colon cancer: a randomized study. Cancer Chemother Pharmacol 75(1):37-47

43. Eisenhauer EA, Therasse P, Bogaerts J, Schwartz LH, Sargent D, Ford R, Dancey J, Arbuck S, Gwyther S, Mooney M et al (2009) New response evaluation criteria in solid tumours: revised RECIST guideline (version 1.1). Eur J Cancer 45(2): 228-247

44. U.S. Department of Health And Human Services: Common Terminology Criteria for Adverse Events v4.03 (CTCAE). Available at: http://evs.nci.nih.gov/ftp1/CTCAE/CTCAE 4.03 2010-06-14_QuickReference_5x7.pdf. Accessed 24 Nov 2014

45. U.S. Food and Drug Administration: Code of Federal Regulations (21CFR312.32). Available at: http://www.accessdata.fda.gov/ scripts/cdrh/cfdocs/cfcfr/cfrsearch.cfm?fr=312.32. Accessed 24 Nov 2014

46. Baggott JE, Tamura T (1999) Bioactivity of orally administered unnatural isomers, [6R]-5-formyltetrahydrofolate and [6S]-5,10methenyltetrahydrofolate, in humans. Biochim Biophys Acta 1472(1-2):323-332 
47. Straw JA, Szapary D, Wynn WT (1984) Pharmacokinetics of the diastereoisomers of leucovorin after intravenous and oral administration to normal subjects. Cancer Res 44(7):3114-3119

48. Schilsky RL, Ratain MJ (1990) Clinical pharmacokinetics of highdose leucovorin calcium after intravenous and oral administration. J Natl Cancer Inst 82(17):1411-1415

49. Kirsch SH, Herrmann W, Eckert R, Geisel J, Obeid R (2013) Factors affecting the distribution of folate forms in the serum of elderly German adults. Eur J Nutr 52(2):497504

50. Taflin H, Wettergren Y, Odin E, Derwinger K (2014) Folate levels measured by LC-MS/MS in patients with colorectal cancer treated with different leucovorin dosages. Cancer Chemother Pharmacol 74(6):1167-1174

51. Emmanouilides C, Yermetaki T, Serpanou A, Sapountzi E, Mantziari P, Titopoulos I, Filippou D (2010) Feasibility study of dose-dense biweekly administered pemetrexed in patients with non-small cell lung cancer. Hematol Oncol Stem Cell Ther 3(1): 34-38

52. Takimoto $\mathrm{CH}$, Hammond-Thelin LA, Latz JE, Forero L, Beeram M, Forouzesh B, de Bono J, Tolcher AW, Patnaik A, Monroe P et al (2007) Phase I and pharmacokinetic study of pemetrexed with highdose folic acid supplementation or multivitamin supplementation in patients with locally advanced or metastatic cancer. Clin Cancer Res 13(9):2675-2683

53. Yang TY, Chang GC, Hsu SL, Huang YR, Chiu LY, Sheu GT (2013) Effect of folic acid and vitamin B12 on pemetrexed antifolate chemotherapy in nutrient lung cancer cells. Biomed Res Int 2013:389046

54. European Medicines Agency (2009) Summary of product Characteristics. Pemetrexed (Alimta ${ }^{\circledR}$ ). http://www.ema.europa. eu/docs/en_GB/document_library/EPAR__Product_Information/ human/000564/WC500025611.pdf. Accessed July 2015

55. Louvet C, de Gramont A (2004) Pemetrexed in advanced colorectal cancer. Oncology (Williston Park) 18(13 Suppl 8):56-62 